\title{
Avaliação da Suscetibilidade à Corrosão sob Tensão da ZAC do aço inoxidável AISI 316L em Ambiente de Reator Nuclear PWR
}

\author{
(Stress Corrosion Cracking of Stainless Steel AISI 316L HAZ in PWR Nuclear Reactor Environment)
}

\author{
Mônica Maria de Abreu Mendonça Schvartzman ${ }^{1}$, Marco Antônio Dutra Quinan ${ }^{1}$, Wagner Reis da Costa Campos ${ }^{1}$, Luciana Iglésias \\ Lourenço Lima \\ ${ }^{1}$ Centro de Desenvolvimento da Tecnologia Nuclear, Serviço de Integridade Estrutural/Laboratório de Corrosão, Belo Horizonte, \\ Minas Gerais,Brasil-monicas@cdtn.br,quinanm@cdtn.br,wrcc@cdtn.br \\ ${ }^{2}$ Universidade Federal de Minas Gerais- Programa de Pós Graduação/Engenharia Mecânica \\ Belo Horizonte, Minas Gerais - lill@cdtn.br
}

\begin{abstract}
Resumo
Aços carbono de baixa liga e aços inoxidáveis são amplamente utilizados nos circuitos primários de reatores nucleares do tipo PWR (Pressurized Water Reactor). Ligas de níquel são empregadas na soldagem destes materiais devido a características como elevadas resistências mecânica e à corrosão, coeficiente de expansão térmica adequado, etc. Nos últimos 30 anos, a corrosão sob tensão (CST) tem sido observada principalmente nas regiões das soldas entre materiais dissimilares existentes nestes reatores. Este trabalho teve como objetivo avaliar, por comparação, a suscetibilidade à corrosão sob tensão da zona afetada pelo calor (ZAC) do aço inoxidável austenítico AISI $316 \mathrm{~L}$ quando submetida a um ambiente similar ao do circuito primário de um reator nuclear PWR nas temperaturas de $303^{\circ} \mathrm{C}$ e $325^{\circ} \mathrm{C}$. Para esta avaliação empregou-se o ensaio de taxa de deformação lenta - SSRT (Slow Strain Rate Test). Os resultados indicaram que a CST é ativada termicamente e que a $325^{\circ} \mathrm{C}$ pode-se observar a presença mais significativa de fratura frágil decorrente do processo de corrosão sob tensão.
\end{abstract}

Palavras-chave: Aços carbonos. Aço inoxidável austenítico. Zona afetada pelo calor. Resistência à corrosão sob tensão. Usina PWR.

\begin{abstract}
In pressurized water reactors (PWRs), low alloy carbon steels and stainless steel are widely used in the primary water circuits. In most cases, Ni alloys are used to joint these materials and form dissimilar welds. These alloys are known to accommodate the differences in composition and thermal expansion of the two materials. Stress corrosion cracking of metals and alloys is caused by synergistic effects of environment, material condition and stress. Over the last thirty years, CST has been observed in dissimilar metal welds. This study presents a comparative work between the CST in the HAZ (Heat Affected Zone) of the AISI $316 \mathrm{~L}$ in two different temperatures $\left(303^{\circ} \mathrm{C}\right.$ and $\left.325^{\circ} \mathrm{C}\right)$. The susceptibility to stress corrosion cracking was assessed using the slow strain rate tensile (SSRT) test. The results of the SSRT tests indicated that CST is a thermally-activated mechanism and that brittle fracture caused by the corrosion process was observed at $325^{\circ} \mathrm{C}$.
\end{abstract}

Key-words: Ferritic steel. Austenitic stainless steel. Heat Affected Zone. Stress corrosion cracking resistance. PWR reactor.

\section{Introdução}

O envelhecimento de sistemas, estruturas e componentes de uma usina nuclear devem ser gerenciados de forma a garantir que as margens de segurança requeridas no projeto sejam mantidas ao longo da sua vida útil. Atividades apropriadas de inspeção e monitoração permitem detectar e caracterizar a degradação por envelhecimento destas complexas instalações. Uma vez caracterizada a degradação de um componente, sua integridade estrutural e/ou funcional pode ser avaliada e decisões podem ser tomadas no sentido de reparar ou substituir o componente de forma a manter a instalação em operação segura. Ao mesmo tempo, ações são definidas para inibir os mecanismos de envelhecimento. Ao desenvolvimento coordenado desse

(Recebido em 28/10/2007; Texto Final em 21/06/2009). conjunto de atividades atribui-se o termo gerenciamento de envelhecimento. O gerenciamento de envelhecimento de centrais nucleares vem se tornando atividade fundamental tanto sob o aspecto de segurança como sob o aspecto econômico, quando se procura estender a vida útil de seus componentes [1].

As usinas nucleares são centrais de geração de energia elétrica que utilizam a reação nuclear de fissão como fonte de calor para produção de energia. No Brasil as usinas são do tipo PWR - Pressurized Water Reactor (Reator a Água Pressurizada). $\mathrm{O}$ princípio de funcionamento dessas usinas se baseia no resfriamento do núcleo do reator através de um circuito fechado de água à elevada pressão, denominado circuito primário (Figura 1).

A água aquecida sob alta pressão no circuito primário passa por um trocador de calor (gerador de vapor) onde aquece e transforma em vapor a água do circuito secundário. Esse vapor 
movimenta uma turbina que aciona um gerador elétrico. A energia elétrica gerada chega aos consumidores finais através de redes de distribuição.

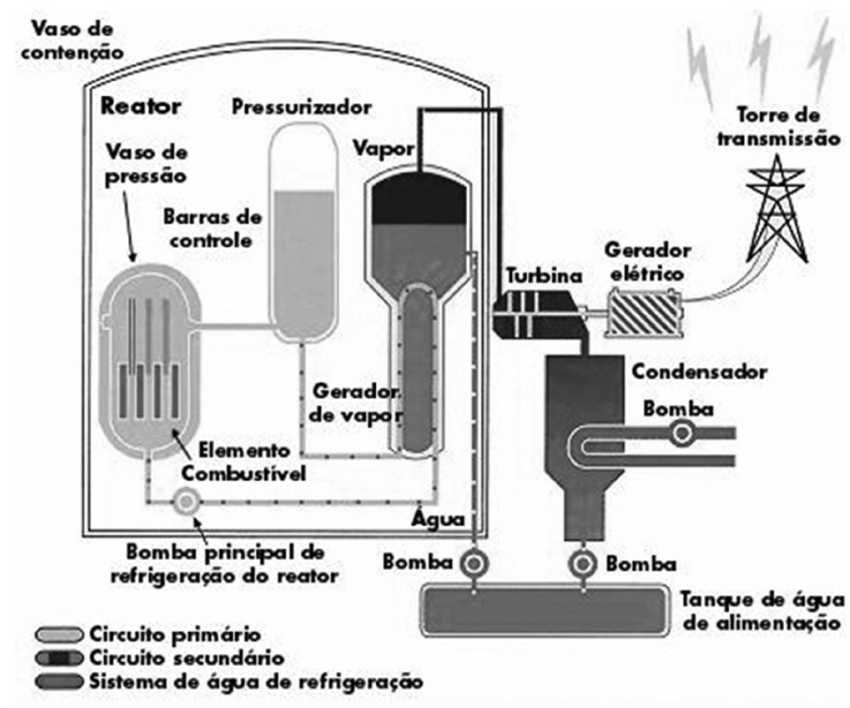

Figura 1. Diagrama esquemático de uma usina nuclear tipo PWR [2].

O Brasil possui duas usinas nucleares do tipo PWR em operação: Angra 1 e Angra 2. Seus reatores foram projetados para operar por 40 anos, havendo possibilidade de estender a vida útil para 60 anos [2].

A corrosão sob tensão (CST) é um dos principais mecanismos de envelhecimento que gradualmente introduz danos nos componentes/estruturas, modificando suas características com o tempo de operação. Esta é uma questão muito importante para empresas proprietárias e operadoras das usinas nucleares, pois afeta a operação e a segurança de importantes componentes, como o reator e o gerador de vapor. Após o aparecimento de uma trinca por CST, a vida útil do componente estará limitada pela velocidade de propagação desta trinca, tornando necessário realizar avaliações que permitam estimar a sua vida útil, bem como estabelecer as condições de manutenção e reposição das partes danificadas [3].

O trincamento por CST, em ambiente do circuito primário de uma usina nuclear do tipo PWR, ocorre principalmente nas soldas dissimilares utilizadas para conectar tubulações de aço inoxidável austenítico a componentes fabricados em aço carbono baixa liga [4,5]. Grande parte das usinas nucleares construídas na década de 80 utilizou como metal de adição, neste tipo de solda, as ligas de níquel 82 e 182 cujo objetivo era acomodar as diferenças metalúrgicas e mecânicas entre os dois materiais.

Este trabalho apresenta uma avaliação da suscetibilidade à corrosão sob tensão da zona afetada pelo calor (ZAC) do aço inoxidável austenítico AISI 316L resultante de sua soldagem com o aço carbono baixa liga ASTM A-508 classe 3, utilizandose como metais de adição os eletrodos de liga de níquel 82 e 182. O estudo foi realizado em ambiente químico similar ao do circuito primário de uma usina nuclear PWR nas temperaturas de $303^{\circ} \mathrm{C}$ e $325^{\circ} \mathrm{C}$. Este trabalho faz parte de um estudo mais amplo onde será avaliada a suscetibilidade à CST das diferentes regiões da solda dissimilar, tais como as ZACs do aço carbono e do aço inoxidável, a região do amanteigamento e a solda propriamente dita, no mesmo meio.

\subsection{Considerações sobre a CST em componentes de usinas nucleares}

A corrosão sob tensão (CST) consiste de um processo de degradação para o qual contribuem a presença simultânea de um ambiente agressivo, de tensões de tração e de materiais suscetíveis, além de um tempo para que o fenômeno ocorra [6]. Esta degradação ocorre em materiais que apresentam boa resistência à corrosão generalizada tais como ligas de níquel, aços inoxidáveis austeníticos, ligas de alumínio, ligas de titânio, etc. Vários modelos para explicar este fenômeno têm sido propostos, mas ainda não existe um consenso sobre o seu mecanismo $[3,6,7]$. Cada par material-meio apresenta suas peculiaridades.

A suscetibilidade de ligas metálicas à CST depende de fatores como, composição química, microestrutura, processo de fabricação e tratamento térmico sofrido pelo material. Os teores de carbono e cromo aparecem como variáveis importantes quando se avalia a composição química. O tamanho de grão e a presença e localização de inclusões e precipitados são também variáveis relevantes na avaliação da resistência de materiais a este fenômeno [8].

Duas principais fontes de tensão são capazes de promover o processo de CST, as tensões resultantes das condições de operação (pressão, temperatura e carregamento mecânico) e as tensões residuais (provenientes de soldagem, operações de conformação mecânica, tratamento mecânico superficial, transformações de fase, etc.). As tensões existentes durante a operação são consideradas nos projetos das plantas nucleares e devem obedecer a normas e códigos específicos. Entretanto, elevadas tensões residuais podem ser criadas durante os processos de fabricação e de soldagem. As tensões residuais decorrentes da soldagem podem ser maiores do que as tensões de operação e tendem a ser uma força motriz dominante para a iniciação e o crescimento de trincas por CST [7, 9].

O meio e a temperatura de operação também são fatores que contribuem de maneira marcante para a CST. As concentrações de oxigênio e hidrogênio, o potencial de corrosão e o pH da solução desempenham um importante papel neste processo [9]. Locais que operam a elevadas temperaturas exibem trincas mais rapidamente do que regiões onde existam menores temperaturas. Este processo é ativado termicamente e pode ser representado pela lei de Arrhenius [3,6].

Trincas decorrentes deste processo corrosivo podem ser transgranulares ou intergranulares. Porém, macroscopicamente, são sempre perpendiculares ao sentido de aplicação das cargas. Fraturas transgranulares são menos comuns que as intergranulares, mas ambas podem existir em um mesmo sistema ou na mesma região falhada, dependendo das condições existentes. O comportamento da falha é característico daquele apresentado por um material frágil, embora as ligas metálicas normalmente suscetíveis sejam intrinsecamente dúcteis $[3,6]$.

Este tipo de degradação tem sido observado em soldas dissimilares existentes em diversas usinas nucleares em todo o 
mundo, sendo que a iniciação de trincas ocorre somente após longos períodos de operação (da ordem de 2 a 3 décadas). Vários estudos realizados, desde a década de 80 , têm demonstrado que as ligas de níquel 82 e 182 são suscetíveis ao fenômeno da CST quando utilizadas em ambiente do circuito primário de reatores PWR [10,11]. Por outro lado, tomava-se como base que os aços inoxidáveis austeníticos não eram suscetíveis à CST quando submetidos às mesmas condições de operação. Contudo, recentemente, tem sido reportado que estes materiais sofrem degradação por CST em água hidrogenada e desaerada de modo similar à observada nas ligas de níquel 600, 82 e 182 [12,13].

\subsection{Considerações sobre soldas dissimilares existentes em usinas nucleares PWR}

As soldas entre dois metais diferentes, denominadas soldas dissimilares, são utilizadas em diversos segmentos da indústria. No caso específico de usinas nucleares PWR tais soldas são comumente utilizadas para conectar tubulações de aço inoxidável austenítico a vasos de pressão de aço carbono baixa liga. As peculiaridades destas juntas estão relacionadas com fatores como, o tipo de usina nuclear, o local de aplicação e os materiais envolvidos. As soldas dissimilares podem ocorrer de forma direta entre os dois materiais, após o amanteigamento de um deles ou empregando-se uma peça intermediária entre os dois materiais $[14,15]$.

$\mathrm{Na}$ Usina Nuclear de Angra 1, assim como em usinas semelhantes, a soldagem dissimilar é realizada em três etapas. $\mathrm{Na}$ primeira é aplicado um amanteigamento no aço carbono baixa liga (aço ASTM A-508) com espessura final variando entre $5 \mathrm{~mm}$ e $8 \mathrm{~mm}$. Para isto utiliza-se como metal de adição a liga de níquel 82 e o processo de soldagem a arco manual GTAW (Gas Tungsten Arc Welding). O amanteigamento é uma alternativa benéfica no sentido de acomodar as diferenças na composição e nas propriedades existentes entre os dois materiais, tais como coeficientes de expansão térmica e condutividade térmica $[14,16]$.
A segunda etapa consiste de um tratamento térmico para o alívio das tensões geradas pelo amanteigamento, seguido da usinagem da superfície amanteigada para obtenção do perfil do chanfro de soldagem. A duração do tratamento térmico é determinada pela espessura do componente de aço carbono e pelo número de camadas do amanteigamento. Na terceira etapa é realizada a união do aço ASTM A-508 amanteigado ao aço AISI 316L utilizando-se o processo GTAW e tendo como metal de adição a liga de níquel 82 nos passes de raiz. O preenchimento da junta é feito com a liga de níquel 182 empregando-se o processo de soldagem a arco manual SMAW (Shielded Metal Arc Welding). A utilização do pré aquecimento é recomendada para materiais com elevado teor de carbono equivalente e grandes espessuras. O pré aquecimento promove a redução da velocidade de resfriamento, que diminui a probabilidade de formação de martensita na ZAC do aço carbono e do trincamento a quente nos materiais envolvidos. Nesta etapa, a utilização de metais de adição fabricados em liga de níquel é frequentemente recomendada, pois esta liga promove uma melhor combinação entre os coeficientes de expansão térmica dos materiais base aço inoxidável e aço carbono [17-19]. O tratamento térmico pós soldagem poderá ou não ser realizado.

\section{Materiais e Métodos}

\subsection{Caracterização do metal base e dos metais de adição}

A soldagem foi realizada utilizando-se como metal base chapas forjadas de aço carbono ferrítico ASTM A-508 classe 3 e de aço inoxidável austenítico AISI 316L, ambas com $31 \mathrm{~mm}$ de espessura, $130 \mathrm{~mm}$ de largura e $300 \mathrm{~mm}$ de comprimento. Como metal de adição foram empregados o eletrodo revestido AWS A5.11 ENiCrFe-3 (liga de níquel 182) e o arame AWS A5.14 ENiCr-3 (liga de níquel 82), com diâmetros de 4 mm e 2,4 mm, respectivamente. A composição química nominal dos metais de base e dos metais de adição é apresentada na Tabela 1.

Tabela 1. Composição química nominal das ligas utilizadas no processo de soldagem (\% peso).

\begin{tabular}{|c|c|c|c|c|c|c|c|c|c|}
\hline \multirow{2}{*}{ Liga } & \multicolumn{10}{|c|}{ Composição Química (\% peso) } \\
\cline { 2 - 11 } & $\mathrm{C}$ & $\mathrm{Mn}$ & $\mathrm{Cr}$ & $\mathrm{Mo}$ & $\mathrm{Ni}$ & $\mathrm{Si}$ & $\mathrm{Fe}$ & $\mathrm{Nb}+\mathrm{Ta}$ & $\mathrm{Ti}$ \\
\hline A508 (Cl3) & $0,15-0,25$ & $1,2-1,5$ & $0,025-0,15$ & $0,15-0,6$ & $0,4-1,0$ & $0,15-0,4$ & & - & - \\
\hline AISI 316L & 0,03 & - & $16-18$ & $2-3$ & $10-14$ & 0,75 & & - & - \\
\hline 82 & 0,1 & $2,5-3,5$ & $18-22$ & - & $67 m i n$. & 0,5 & 3,0 & $2,0-3,0$ & 0,75 \\
\hline 182 & 0,1 & $5,0-9,5$ & $13-17$ & - & 59 min. & 1,0 & 10 & $1,0-2,5$ & 1,0 \\
\hline
\end{tabular}

\subsection{Procedimento de soldagem}

A soldagem foi realizada manualmente. As chapas foram pré aquecidas a $150{ }^{\circ} \mathrm{C}$ antes da soldagem e a temperatura máxima inter passes foi de $200^{\circ} \mathrm{C}$. Inicialmente, foram aplicadas camadas de amanteigamento no aço carbono ASTM A-508 utilizandose a liga de níquel 82 e o processo de soldagem GTAW. O gás de proteção empregado foi o Argônio (Ar) com vazão de $20 \mathrm{l} / \mathrm{min}$. A espessura resultante foi de cerca de $8 \mathrm{~mm}$. Após o amanteigamento a peça foi usinada e tratada termicamente a uma temperatura de $600^{\circ} \mathrm{C}$ por 2 horas, para alívio de tensões residuais.

A união do aço carbono amanteigado e do aço inoxidável foi realizada utilizando-se o processo GTAW com arame da liga níquel 82 nos três passes de raiz. O preenchimento da junta foi feito com a liga de níquel 182 pelo processo SMAW. Não foi realizado tratamento térmico pós soldagem. Os parâmetros de soldagem utilizados estão resumidos na Tabela 2. Após o 
Tabela 2. Parâmetros utilizados nas três etapas da soldagem do aço carbono ASTM A-508 e o aço AISI 316L.

\begin{tabular}{|c|c|c|c|c|c|c|}
\hline & Processo & $\begin{array}{c}\text { Metal de } \\
\text { Adição }\end{array}$ & $\begin{array}{c}\text { Diâmetro do } \\
\text { eletrodo }(\mathbf{m m})\end{array}$ & $\begin{array}{c}\text { Corrente } \\
(\mathbf{A})\end{array}$ & Tensão (V) & $\begin{array}{c}\text { Velocidade de } \\
\text { soldagem (mm/s) }\end{array}$ \\
\hline Amanteigamento & GTAW & 82 & 2,4 & $90-130$ & $17,5-18$ & $1,8-3,0$ \\
\hline $1-3$ (Raiz) & GTAW & 82 & 2,4 & $126-168$ & $20-22$ & $1-1,2$ \\
\hline $4-37$ & SMAW & 182 & 4 & $119-135$ & $22-26$ & $1-3,5$ \\
\hline
\end{tabular}

término da soldagem, a peca-teste foi cortada e amostras da zona afetada pelo calor do aço AISI 316L foram retiradas, na direção longitudinal, próximas à raiz.

\subsection{Análise Metalográfica}

Foram preparadas amostras para análise metalográfica da ZAC do aço inoxidável $316 \mathrm{~L}$. As amostras foram analisadas empregando-se técnicas de microscopia ótica com sistema de aquisição e análise de imagem, microscopia eletrônica de varredura (MEV). As amostras foram lixadas, polidas até $1 \mu \mathrm{m}$ e atacadas eletroliticamente em solução $10 \%$ de ácido oxálico ( $2 \mathrm{~V}$ por 2 minutos).

\subsection{Ensaios de corrosão sob tensão}

O ensaio de taxa de deformação lenta, SSRT (Slow Strain Rate Test) foi empregado para avaliar a suscetibilidade à corrosão sob tensão no meio estudado. Esta técnica é um caso particular do ensaio de tração, conduzido sob regime de deformação lenta, em meio corrosivo. Parâmetros relacionados à variação de ductilidade do material (tempo de falha, deformação plástica ou total e limite de resistência) obtidos nas curvas tensão versus deformação, a observação visual da região fraturada e a morfologia da fratura são utilizados como indicadores da resistência do material à CST no meio estudado. Estes resultados devem ser comparados com os resultados de um teste similar conduzido em um ambiente inerte para analisar a resistência ou suscetibilidade à corrosão sob tensão no meio estudado e eliminar os efeitos que não foram causados por CST [20].

Esta técnica é comprovada como eficaz em avaliações comparativas de meios, variáveis metalúrgicas ou de condições de operação, as quais podem afetar a resistência à CST de um material. Mas, no caso deste ensaio, como a iniciação de trincas por CST é acelerada pela aplicação de deformação dinâmica na seção útil do corpo-de-prova, os resultados podem não reproduzir quantitativamente as condições em serviço. Desta forma, quando o objetivo é fornecer dados para serem utilizados em projetos, outros métodos devem ser utilizados em conjunto.

Neste trabalho, os ensaios com taxa de deformação lenta foram executados segundo a norma ASTM G129-95 [21], empregando-se uma taxa de deformação de $3 \times 10^{-7} \mathrm{~s}^{-1}$, a qual permite a observação dos efeitos da corrosão sob tensão no meio estudado. Eles foram conduzidos em uma solução de composição química similar à de operação do circuito primário de um reator PWR (água deionizada contendo 1000 ppm de boro, 1,5-2,0 ppm de lítio, $<5 \mathrm{ppb}$ de oxigênio dissolvido e $25 \mathrm{~cm}^{3} \mathrm{H}_{2} / \mathrm{kg}$
$\mathrm{H}_{2} \mathrm{O}$ ) à pressão de $12,5 \mathrm{MPa}$ (meio teste) e $\mathrm{em}_{2}$ (meio neutro). Os ensaios foram realizados no aço AISI $316 \mathrm{~L}$ no meio teste à temperatura de $325^{\circ} \mathrm{C}$, e na ZAC do aço AISI 316L no meio teste à $303^{\circ} \mathrm{C}$ e $325^{\circ} \mathrm{C}$ e em meio neutro à $325^{\circ} \mathrm{C}$.

A avaliação as suscetibilidade à CST foi realizada em três etapas. Inicialmente foi comparado o comportamento frente à CST do aço AISI 316L e da ZAC deste aço, no meio teste à $325^{\circ} \mathrm{C}$. Na segunda etapa foi avaliada a influência da temperatura no processo de CST da ZAC do aço AISI 316L no meio teste, nas temperaturas de $303^{\circ} \mathrm{C}$ e $325^{\circ} \mathrm{C}$. Na etapa final, comparouse o comportamento da ZAC do aço AISI 316L no meio teste e em meio neutro à $325^{\circ} \mathrm{C}$. Foram realizados dois ensaios para cada condição estudada.

Os corpos-de-prova (CPs) utilizados nos ensaios de CST foram usinados de acordo com as normas ASTM G49 [22] e ASTM E8 [23], com comprimento útil de $12 \mathrm{~mm}$ e diâmetro de 2,4 mm (Figura 2).

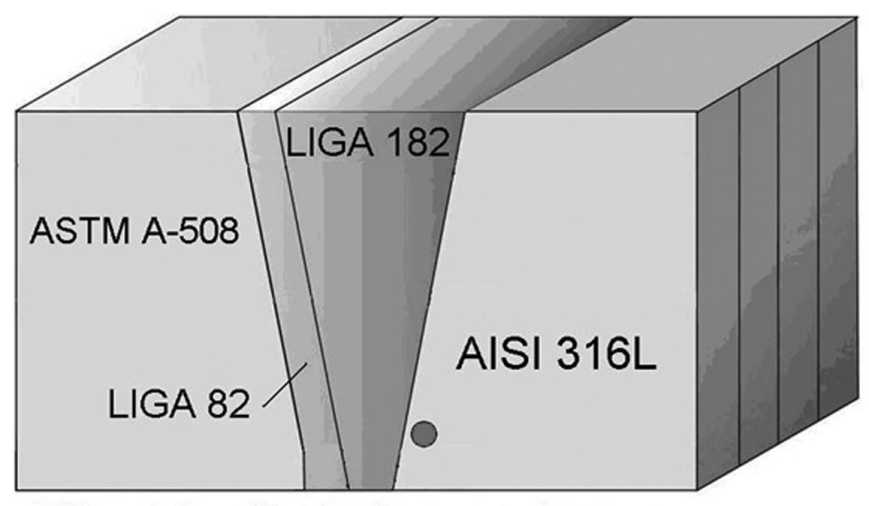

local de retirada do corpo de prova

(a)

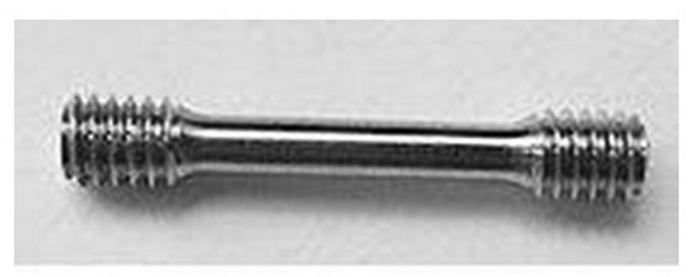

(b)

Figura 2. (a) Local de retirada das amostras. (b) corpo-de-prova utilizado nos ensaios de corrosão sob tensão. 


\subsection{Instalação para ensaios de corrosão sob tensão}

A instalação empregada nos ensaios de CST é composta de uma autoclave com um sistema de tração servohidráulico, controlado por deslocamento ou carga, e de um circuito hidráulico com um sistema de circulação do meio aquoso. $\mathrm{O}$ deslocamento é medido por um sensor de posição linear (linear variable differential transformer - LVDT) e a carga com uma célula de carga. A autoclave é aquecida externamente por um forno elétrico controlado continuamente por um sistema PID
(Proporcional - Integral - Diferencial). Durante a execução dos ensaios são realizadas medições "on line" de carga, deslocamento, temperatura, pressão, condutividade e concentração de oxigênio. Um software de aplicação desenvolvido no ambiente LabVIEW ${ }^{\circledR}$ é responsável pela aquisição de dados e sua representação gráfica. A instalação permite a utilização de corpos-de-prova de tração e tração compacto. $\mathrm{O} \mathrm{CP}$ é isolado eletricamente do sistema por meio de pinos anodizados. A Figura 3 mostra um diagrama esquemático da instalação e a Tabela 3 descreve seus principais parâmetros técnicos.

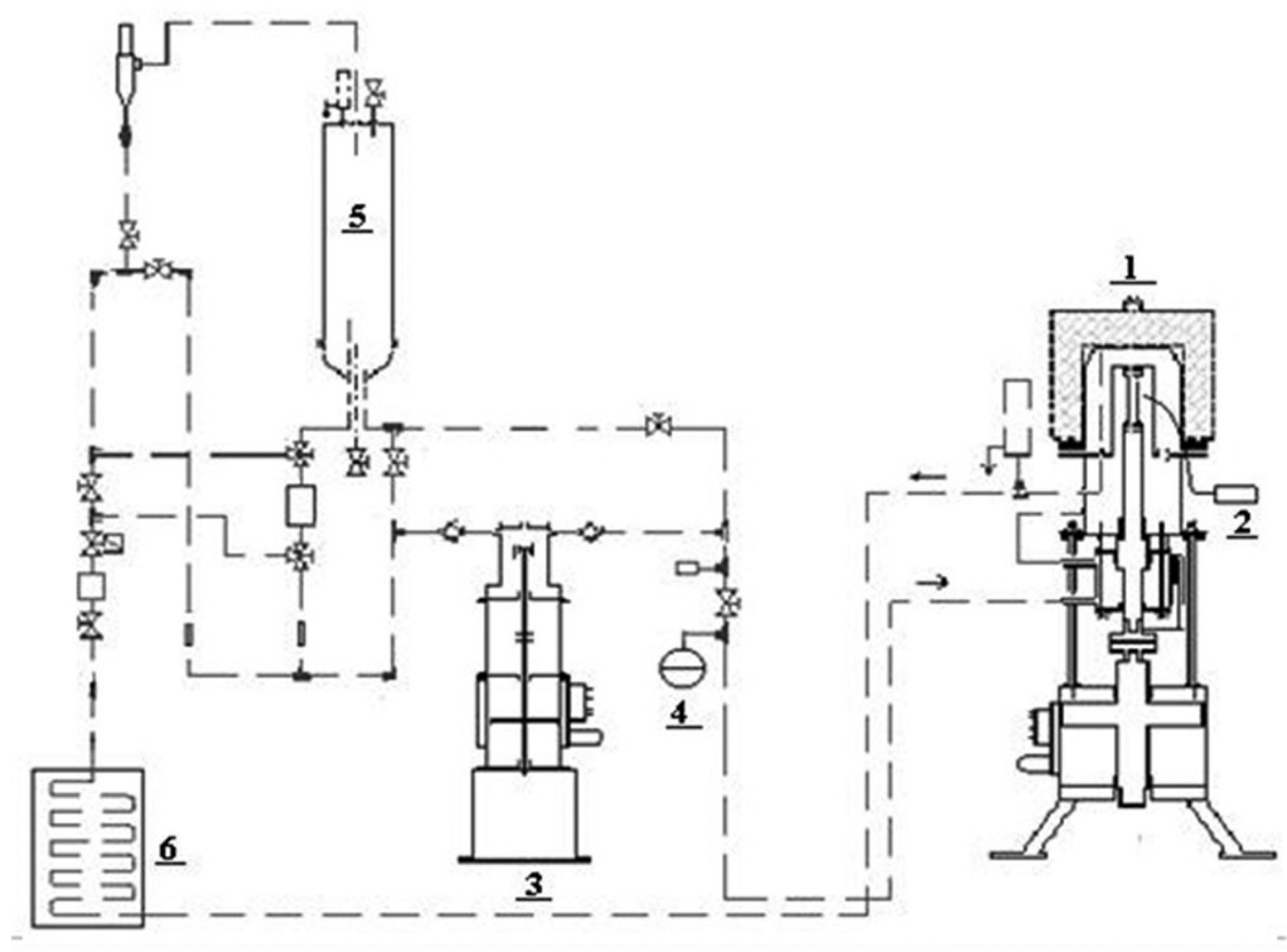

Figura 3. Diagrama esquemático da instalação para ensaios de CST: 1) autoclave; 2) eletrodo de Pt; 3) bomba de circulação do meio; 4) acumulador de pressão; 5) tanque de armazenamento do meio; 6) resfriador.

Tabela 3. Principais parâmetros técnicos da instalação para ensaios de CST em ambiente de reator nuclear.

\begin{tabular}{|l|l|l|}
\hline \multicolumn{1}{|c|}{ Item } & \multicolumn{1}{|c|}{ Parâmetro } & \multicolumn{1}{c|}{ Valor } \\
& Temperatura máxima & $325^{\circ} \mathrm{C}$ \\
& Pressão máxima & $12,5 \mathrm{MPa}$ \\
\hline \multirow{3}{*}{ Sistema de tração } & Carregamento Máximo & $60 \mathrm{kN}$ \\
& Taxa de Deslocamento Mínima & $10^{-10} \mathrm{~m} \cdot \mathrm{s}^{-1}$ \\
& Taxa de Deslocamento Máxima & $10^{-4} \mathrm{~m} \cdot \mathrm{s}^{-1}$ \\
\hline
\end{tabular}




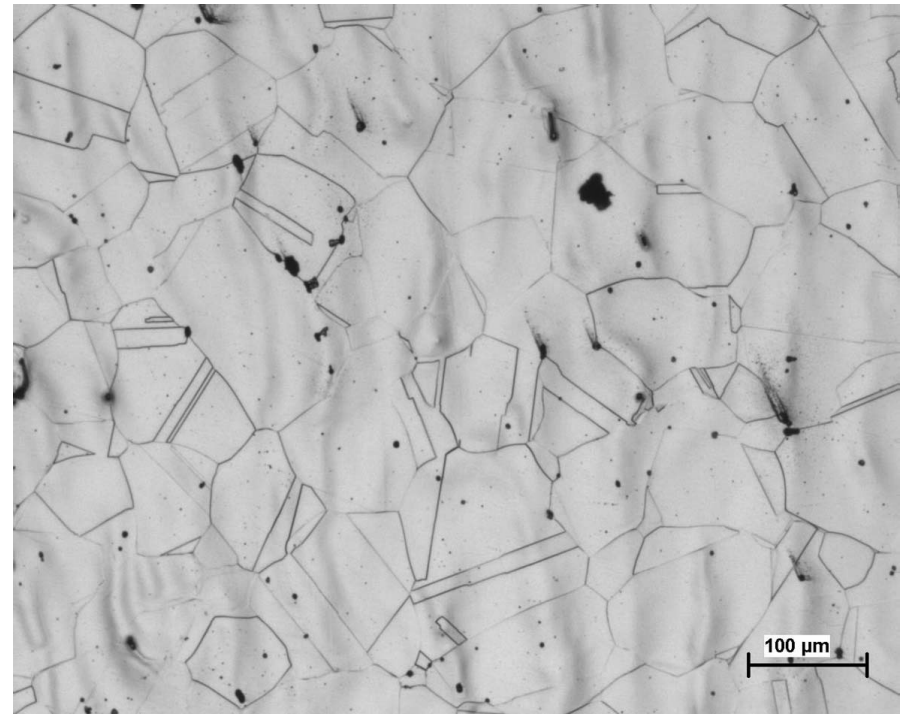

(a)

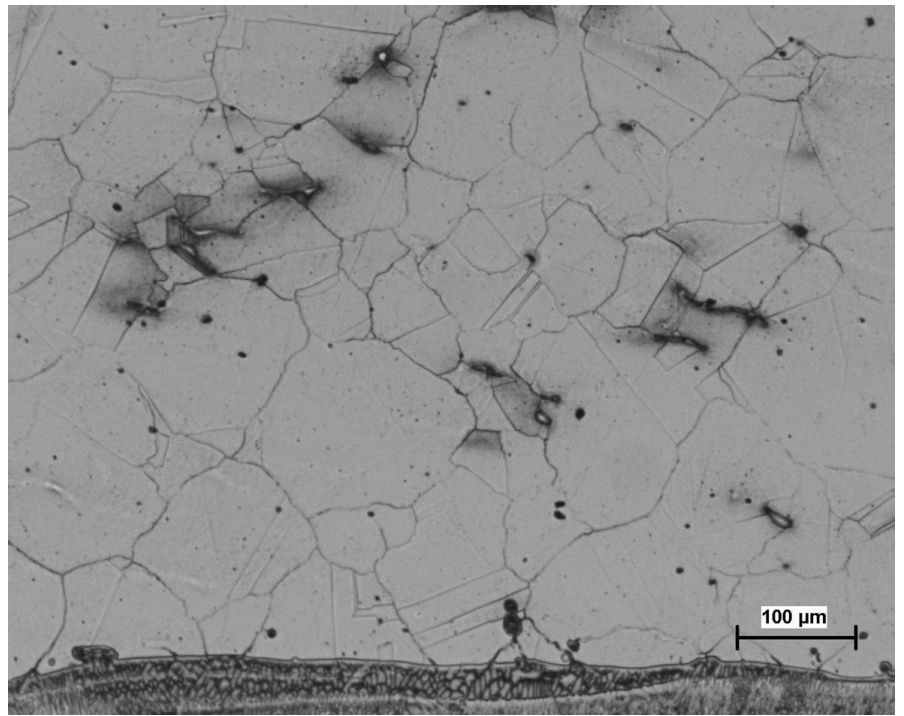

(,b)

Figura 4. (a) Micrografia do metal de base (aço AISI 316L), (b) micrografia da ZAC do aço AISI 316L. Ataque eletrolítico com ácido oxálico $10 \%, 2 \mathrm{~V}$ por 2 minutos.

\section{Resultados e Discussão}

\subsection{Caracterização macro e microestrutural}

O metal base (aço AISI 316L) possui uma microestrutura austenítica de grãos equiaxiais e maclas, apresentando pequena quantidade de ferrita delta (Figura 4a). O tamanho médio de grão foi de $55 \mu \mathrm{m}$. A ZAC do metal base também possui microestrutura austenítica com alguns precipitados (Figura 4b) e também a presença de fase sigma próximo a linha de fusão (Figura 5). O tamanho médio de grão da ZAC foi maior do que o observado no metal base, cerca de $72 \mu \mathrm{m}$.

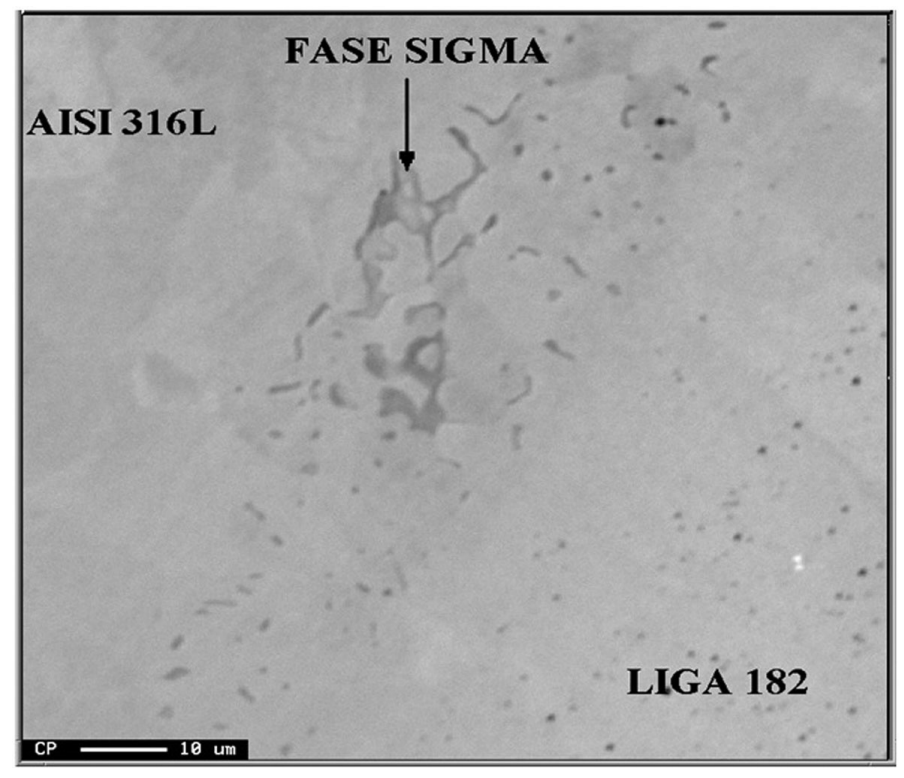

Figura 5. Micrografia da ZAC do aço AISI 316L mostrando a presença de fase sigma. Ataque químico com reagente Marble.
Na Figura 6 é mostrado o perfil de microdureza Vickers, carga de 500 gramas (HV- 500g), da junta soldada. Na ZAC do metal base (AISI 316L), até aproximadamente 12,5 mm da linha de fusão, os valores de microdureza aumentaram, provavelmente devido a tensões residuais, aos precipitados e a fase sigma gerados durante o processo de soldagem.

\section{Microdureza Vicker X Distância da LF}

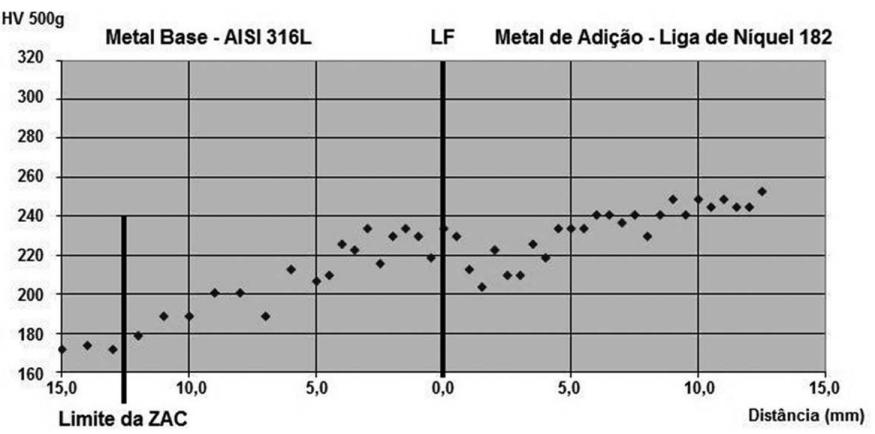

Figura 6. Perfil de microdureza Vickers (HV 0,5) da região da solda, entre $15 \mathrm{~mm}$ do metal base - AISI 316L com ZAC, e 15 mm no metal de solda - liga de níquel 182.

\subsection{Avaliação da corrosão sob tensão}

O ensaio de tração sob taxa de deformação lenta (SSRT) se comprova como um método eficaz no estudo da resistência à corrosão sob tensão de materiais. De acordo com a norma ASTM G 129-95, o tempo de ruptura, o limite de resistência mecânica e a deformação total são três dos possíveis parâmetros empregados na análise da suscetibilidade à CST. Estes parâmetros, assim como a análise da morfologia das fraturas dos corpos-deprova foram utilizados para comparação do comportamento do material em CST, nas condições estudadas. Na avaliação da morfologia das fraturas foi considerado que as fraturas frágeis 
foram promovidas pelo processo de CST.

A avaliação da suscetibilidade à corrosão sob tensão do aço AISI 316L e de sua ZAC foi efetuada através de ensaios de tração realizados à taxa de deformação de $3 \times 10^{-7} \mathrm{~s}^{-1}$, tanto em meio similar ao do circuito primário de um reator PWR (descrito no item 2.4) quanto em meio neutro $\left(\mathrm{N}_{2}\right)$. A Figura 7a mostra as diferenças no comportamento do metal base e da ZAC do aço AISI 316L demonstradas nos ensaios de SSRT, no meio teste e na temperatura de $325^{\circ} \mathrm{C}$. Observa-se que a ZAC apresentou menores valores de limite de resistência e ductilidade, indicando sua maior suscetibilidade à CST. Este comportamento foi atribuído ao aumento da dureza da ZAC provocado pelas tensões

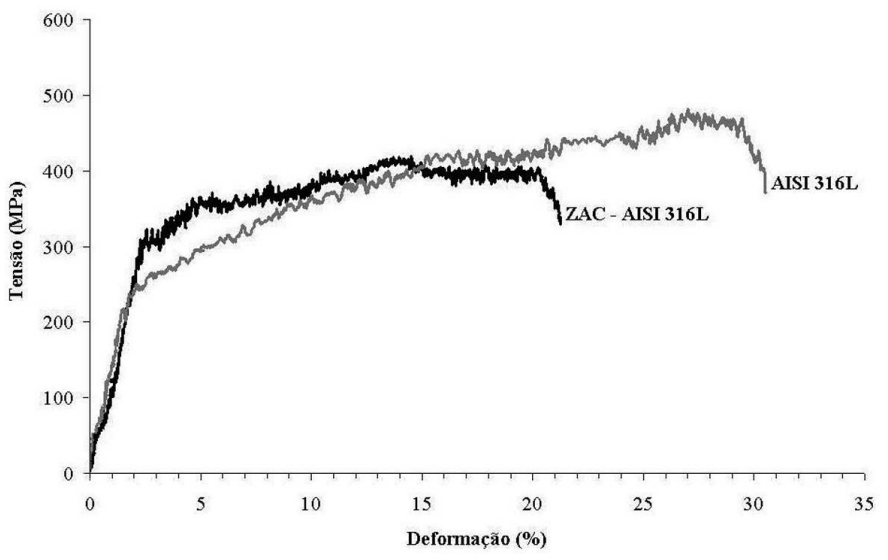

(a) geradas durante os ciclos térmicos de soldagem. A Figura $7 \mathrm{~b}$ e a Tabela 4 apresentam as curvas tensão versus deformação para a ZAC do aço AISI 316L e as propriedades mecânicas, respectivamente, obtidas nos ensaios de SSRT realizados nas temperaturas de $303^{\circ} \mathrm{C}$ e $325^{\circ} \mathrm{C}$. Os valores expressos nesta tabela referem-se aos resultados obtidos nos dois ensaios realizados para cada condição. É evidente, nos resultados destes ensaios, a diferença na resposta do material quando exposto ao meio teste e a diferentes temperaturas. Observa-se que ocorreu uma redução do limite de resistência e da ductilidade do material com a elevação da temperatura. Esta redução foi atribuída ao processo de CST que provocou a fragilização do material.

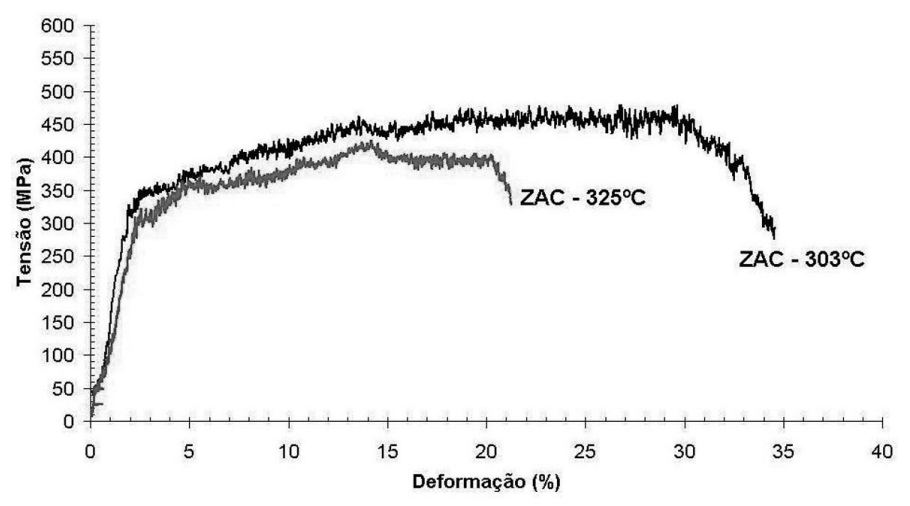

(b)

Figura 7. Ensaios de CST realizados (a) no aço AISI 316L e na ZAC do aço AISI $316 \mathrm{~L}$ em meio teste a $325^{\circ} \mathrm{C}$ e (b) na ZAC do aço AISI $316 \mathrm{~L}$ em meio teste à temperaturas de $303^{\circ} \mathrm{C}$ e $325^{\circ} \mathrm{C}$. Taxa de deformação: $3,0 \times 10^{-7}$.

Tabela 4. Resultados dos ensaios de SSRT, realizados na ZAC do aço AISI $316 \mathrm{~L}$ à $303^{\circ} \mathrm{C}$ e $325^{\circ} \mathrm{C}$.

\begin{tabular}{|c|c|c|}
\hline Condição & UTS (MPa) & Deformação total $(\%)$ \\
\hline ZAC AISI $316 \mathrm{~L} /$ meio teste $/ 303^{\circ} \mathrm{C}$ & $478-492$ & $32-34$ \\
\hline ZAC AISI $316 \mathrm{~L} /$ meio teste $/ 325^{\circ} \mathrm{C}$ & $414-430$ & $17,5-20,5$ \\
\hline
\end{tabular}

As fractografias das superfícies de fratura e das superfícies laterais dos corpos de prova ensaiados em CST à $303^{\circ} \mathrm{C}$ e $325^{\circ} \mathrm{C}$ são mostradas na Figura 8. Observa-se que as superfícies de fratura, nas duas condições, possuem aspecto dúctil no centro dos corpos-de-prova e regiões de fratura frágil transgranular nas bordas, indicando a iniciação de trincas por CST. As superfícies laterais dos CPs também apresentaram trincas secundárias decorrentes da degradação do material por CST. À $303^{\circ} \mathrm{C}$ foi observada a presença de pequenas regiões esparsas com aspecto frágil e nos ensaios à $325^{\circ} \mathrm{C}$, trincas transgranulares, iniciadas na superfície externa, se propagaram para o centro dos CPs em várias regiões, chegando a uma profundidade máxima de cerca de $500 \mu \mathrm{m}$. Segundo Andresen [12] e Ishiyama [24], tanto os aços inoxidáveis sensitizados quanto os não sensitizados podem sofrer CST em ambiente de reator PWR, mas a morfologia das trincas apresentadas pelos aços inoxidáveis não sensitizados é geralmente transgranular. Desta forma, considera-se que a ZAC do aço AISI 316L não sofreu sensitização significativa no processo de soldagem.

Observa-se que a área frágil da superfície de fratura aumentou com a elevação da temperatura de ensaio, o que ficou também evidenciado pela menor estricção do corpo-de-prova. Estes resultados são consistentes com aqueles obtidos nas curvas tensão versus deformação e indicam o aumento da "fragilidade" e da suscetibilidade à corrosão sob tensão do material com a temperatura.

A comparação do comportamento frente à CST da ZAC do aço AISI $316 \mathrm{~L}$ no meio teste e em meio neutro à $325^{\circ} \mathrm{C}$, empregando-se o ensaio de SSRT, é mostrada na Figura 9 e na Tabela 5. Nota-se a influência do meio no processo de CST, evidenciado principalmente pela diminuição da ductilidade do material. As fractografias referentes aos corpos-de-prova ensaiados em $\mathrm{N}_{2}$ (Figura 10) mostram o aspecto dúctil da fratura em toda a sua extensão, tanto nas bordas como no centro, comprovando a ruptura puramente mecânica. Observou-se a presença de estricção próxima à superfície de fratura e a ausência de trincas na superfície lateral. 


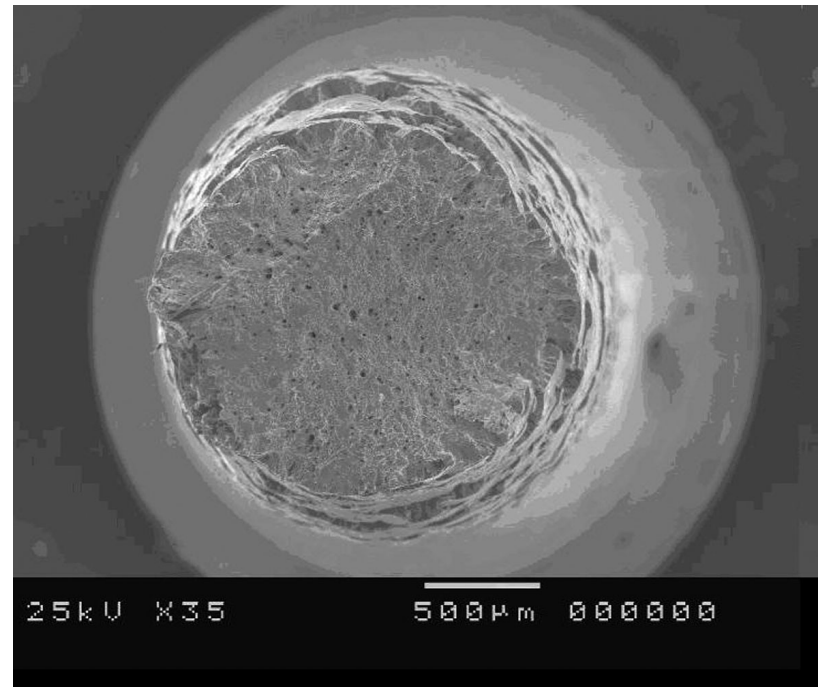

(a)

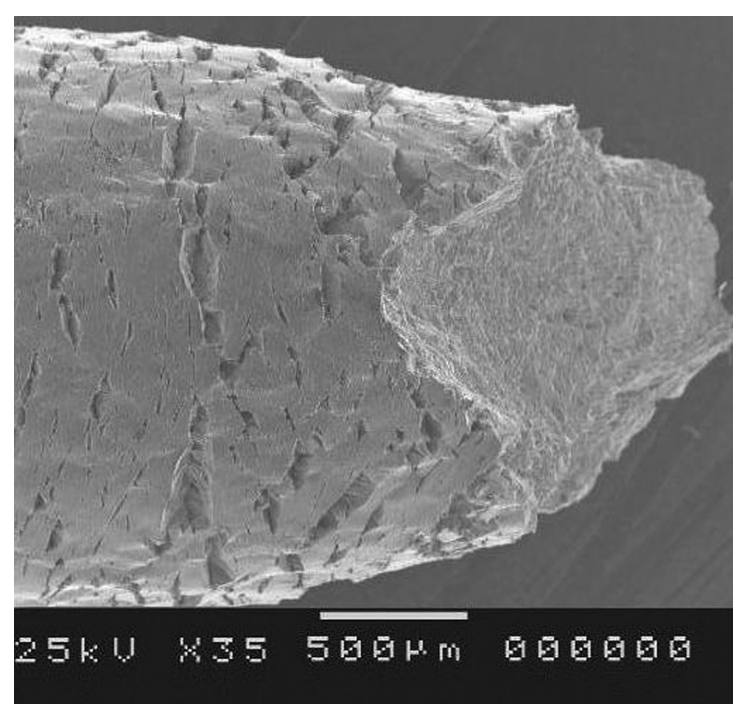

(b)

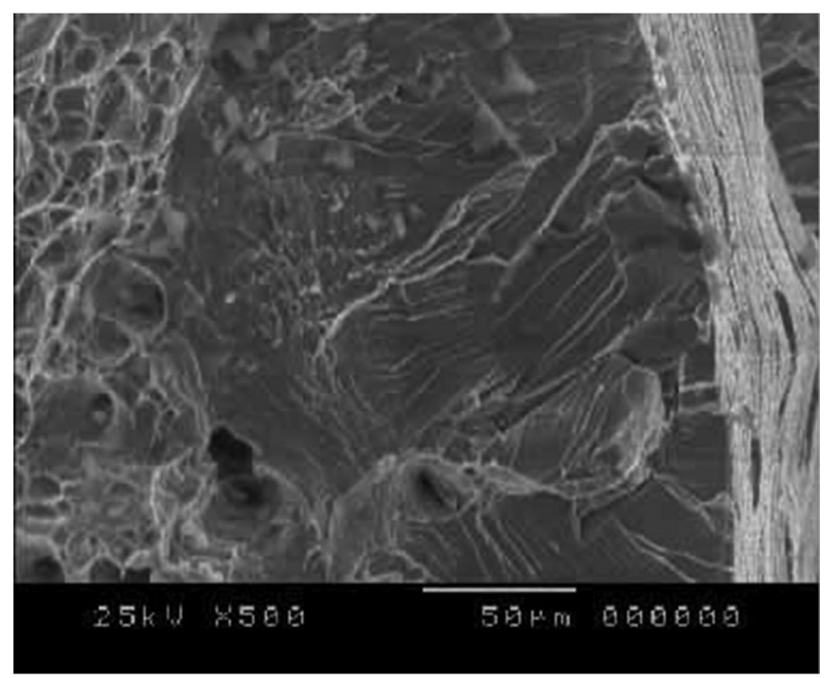

(c)

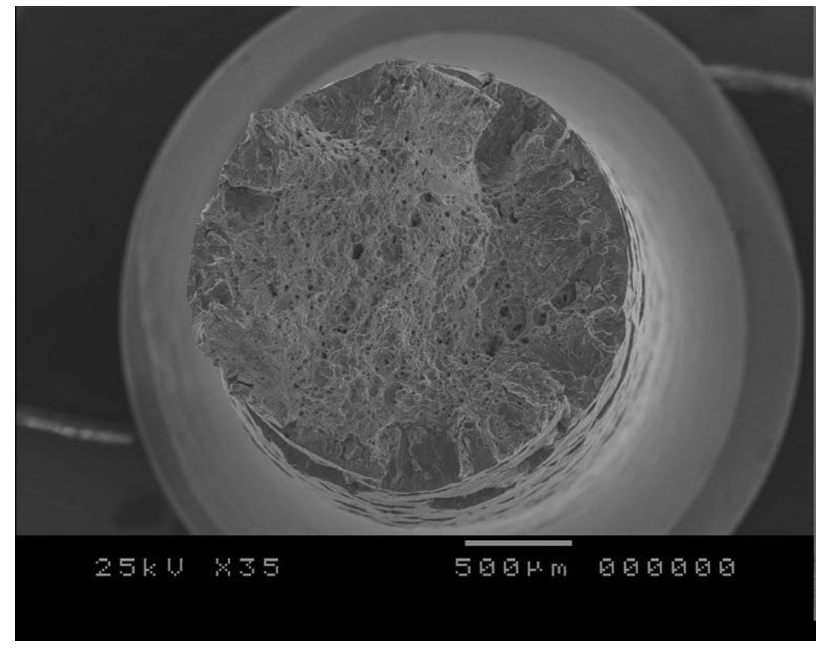

(d)

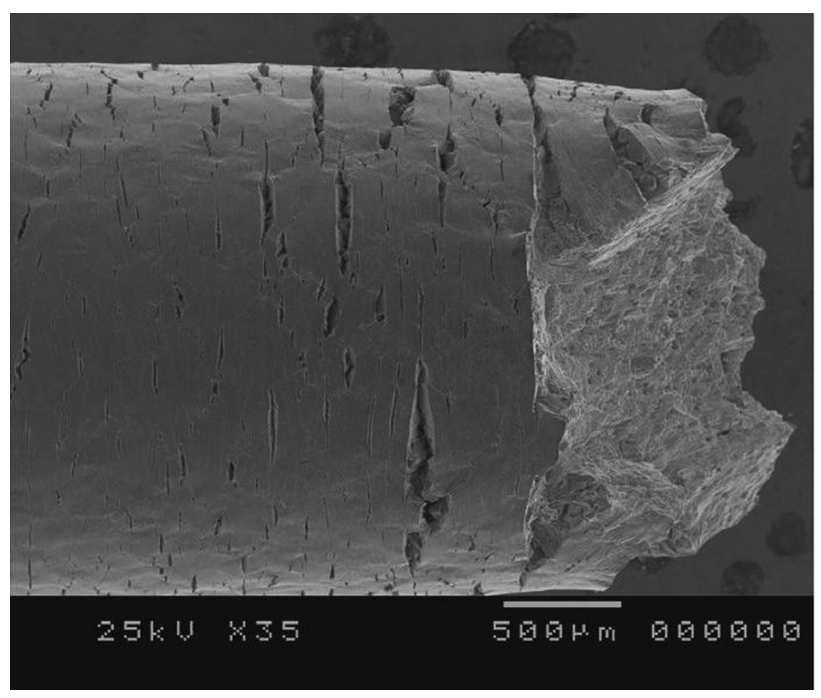

(e)

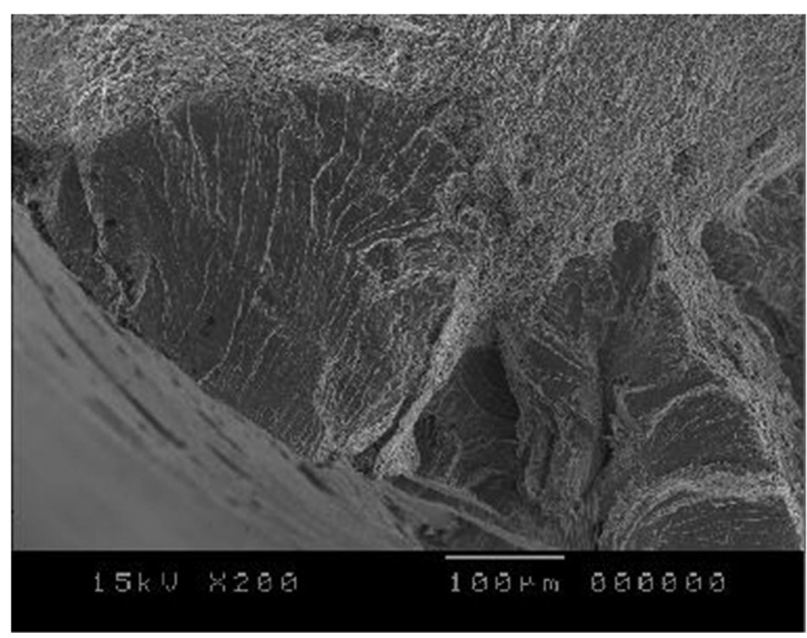

(f)

Figura 8. Imagens obtidas em MEV, das superfícies lateral e de fratura dos corpos de prova ensaiados em CST, nas temperaturas de $303^{\circ} \mathrm{C}(\mathrm{a}, \mathrm{b}$ e c $)$ e $325^{\circ} \mathrm{C}(\mathrm{d}, \mathrm{e}, \mathrm{f})$. 


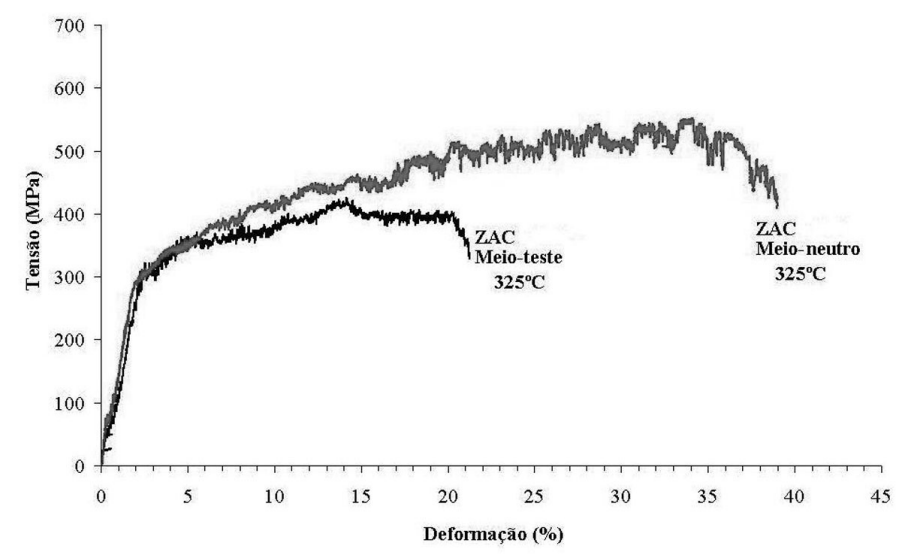

Figura 9. Ensaios de CST realizados na ZAC do aço AISI 316L no meio teste e em meio neutro à temperatura de $325^{\circ} \mathrm{C}$.
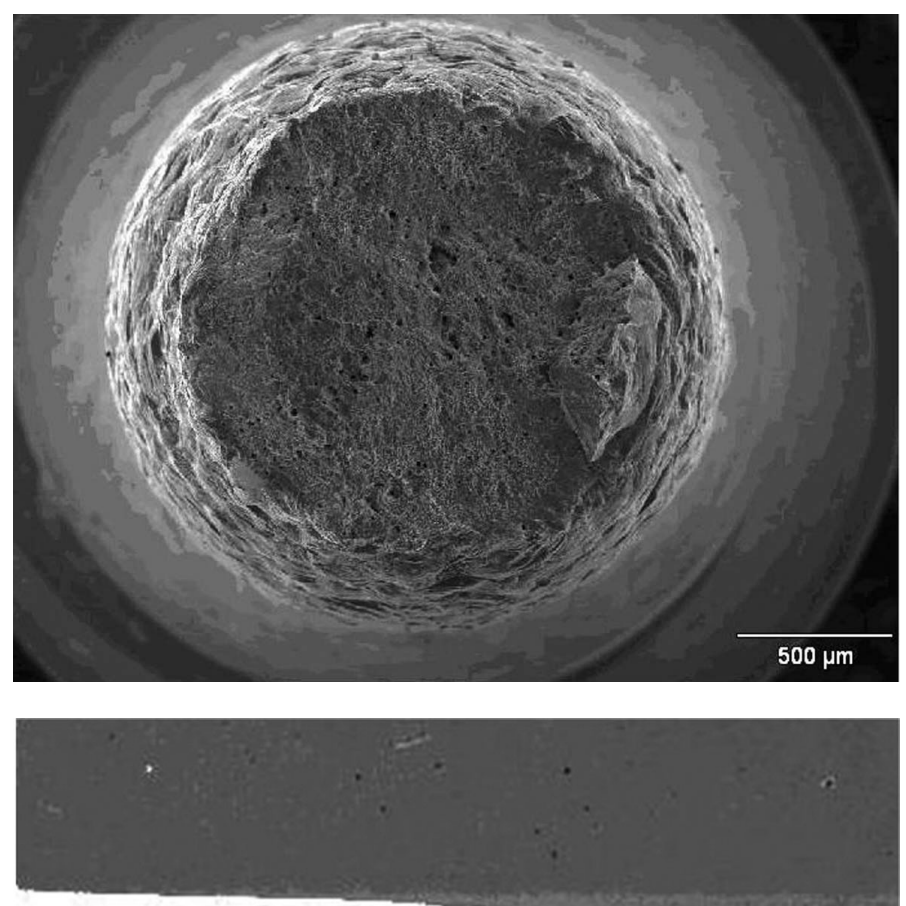

$2.5 \mathrm{~mm}$

Figura 10. Superfícies de fratura resultantes dos ensaios de CST da ZAC do aço AISI 316L em $\mathrm{N}_{2}$ à $325^{\circ} \mathrm{C}$.
Tabela 5. Resultados dos ensaios de SSRT, realizados na ZAC do aço AISI 316L no meio testes e em meio neutro.

\begin{tabular}{|l|c|c|}
\hline \multicolumn{1}{|c|}{ Condição } & $\begin{array}{c}\text { UTS } \\
\text { (MPa) }\end{array}$ & $\begin{array}{c}\text { Deformação } \\
\text { total (\%) }\end{array}$ \\
\hline $\begin{array}{l}\text { ZAC AISI 316L / } \\
\text { meio teste } / 325^{\circ} \mathrm{C}\end{array}$ & 422 & 19 \\
\hline ZAC AISI $316 \mathrm{~L} / \mathrm{N}_{2} / 325^{\circ} \mathrm{C}$ & 553 & 37 \\
\hline
\end{tabular}

\section{Conclusões}

As conclusões deste estudo estão sumarizadas a seguir.

- A ZAC do aço AISI 316L se mostrou suscetível à corrosão sob tensão quando submetida a um ambiente similar ao do circuito primário de um reator PWR. Entretanto, ficou evidenciado o baixo nível de suscetibilidade devido à presença de extensas áreas de fratura dúctil e somente regiões esparsas de aspecto frágil, características do processo de CST.

- Os ensaios realizados mostraram que, a uma maior temperatura a ZAC perdeu resistência mecânica e, particularmente, tenacidade. Evidenciando o maior grau de degradação por CST do material, com a elevação da temperatura no meio estudado.

\section{Agradecimento}

Os autores agradecem aos técnicos Antônio Edicleto G. Soares, Antônio Eugênio de Aguiar e Geraldo Antônio Scoralick Martins pelas contribuições à pesquisa. Agradece-se também à FAPEMIG, ao CNPq, à FINEP e ao CDTN/CNEN pelo suporte financeiro.

\section{Referências Bibliográficas}

[1] JÚLIO, R.B., DI LORENZO, R.F., MANSUR, T.R., Gerenciamento de envelhecimento e extensão de vida de centrais nucleares. In: IX Congresso Brasileiro de Energia, 2002, Rio de Janeiro. Anais...Rio de Janeiro:COPPE/UFRJ, 2002.

[2] Global Energy Systems and Common Analyses - Final Report of Annex X (2005-2008). ETSAP - International Energy Agency Implementing Agreement for a Programme of Energy Technology Systems Analysis. Ed. Gary Goldstein and GianCarlo Tosato, June, 2008.

[3] JONES, R. H. Stress corrosion cracking - materials performance and evaluation. Ohio: American Society of Metals International, 1992.

[4] SCOTT, P.M. An Overview of Materials Degradation by Stress Corrosion in PWRs. Eurocorr- Annual European Corrosion Conference of the European Federation of Corrosion, Nice, Acropolis, 12 - 16 of Sep. 2004.

[5] ALEXANDREANU, B., CHEN, Y., CHOPRA, K.O., CHUNG, M.H., GRUBER, E.E., SOPPET, K.W., SHACK, J. W. Environmentally Assisted Cracking in Light Water Reactors. Argone National Laboratory - NUREG/CR-4667. US. Nuclear Regulatory Commission Office of Nuclear Regulatory Research, Março, 2007. 
[6] JONES, R. H. Stress corrosion cracking. In: Corrosion: Fundamentals, Testing, and Protection, Vol 13A, ASM Handbook, ASM International, 2003, p 879-936.

[7] SEDRICKS, A. J. Stress Corrosion Cracking Test Methods in Corrosion Testing Made Easy, ed. B.C. Syrett, NACE 1990.

[8] SEDRICKS, A. J. Corrosion of Staniless Steel. Second Edition. Princeton, New Jersey. 1996.

[9] DANKO, J. C. Corrosion in the nuclear power industry. In: Corrosion, Vol 13 ASM Handbook, ASM International, 1992 p. 927.

[10] EPRI - Electric Power Research Institute. Review of SCC of Alloys 182,82inPWRPrimary Service.MRP220,2007.Disponível em: www.epriweb.com/public/000000000001015427.pdf.

[11] GOMEZ-BRICEÑO, D., SERRANO, M. Aleaciones Base Niquel em Condiciones de Primario de Los Reactores Tipo PWR. Materiales, Março, 2005.

[12] ANDRESEN, P. L., MORRA, M. M. IGSCC of NonSensitized Stainless Steels in High Temperature Water. Journal of Nuclear Materials, 383, 2008, p. 97-111.

[13] SIREESHA, M., SHANKAR, V., ALBERT, S.K., SUNDARESAN, S. Microstructural Features of Dissimilar Welds Between 316LN Austenitic Stainless Steel and Alloy 800. Materials Science and Engineering A262, 2000, p. 74-82.

[14] MITEV, R., TAYLOR, N. G., General review of dissimilar metal welds in piping systems of pressurized water reactors, including WWER designs. European Commission DG-JRC/IE, Petten, Netherlands, EUR 22469 EN, 2006.

[15] JANG, C., LEE. J., KIM, S. J., JIN, E. T. Mechanical Property Variation Within Inconel 82/182 Dissimilar Metal Weld Between Low Alloy Steel and 316 Stainless Steel. International Journal of Pressure Vessels and Piping, 85, 2007, p.635-646.

[16] FAIDY, C., GILLES, P. Assessment of Dissimilar Weld Integrity: Final Report of the NESC-III project. European Comission, EUR 22510 EM, 2006.

[17] IAEA - International Atomic Energy Agency. Assesment and Management of Ageing of Major Nuclear Power Plant Components Important to Safety - Primary Piping in PWRs. IAEA - TECDOC 1361, 2003.

[18] FELDSTEIN, J.G. Dissimilar Welds With Stainless Steel. In: Welding, Brazing and Soldering, ASM Handbook, ASM International, V.6, 2003, p.1279-1281.

[19] SCHAEFER, A., Dissimilar Metal Weld Failure Problems in Large Steam Generators, Power, 1979, p.68-69.

[20] NATIONAL ASSOCIATION OF CORROSION ENGINEERS - The National Association of Corrosion Engineers. Nace Standard test Method-SSRT Method for Screening Corrosion Resistant Alloys (CRAs) for Stress Corrosion Cracking in Sour Oifield Service - TMO198-2004, 2004.

[21] AMERICAN SOCIETY FOR TESTING AND MATERIALS. ASTM G129 - Standard practice for slow strain rate testing to evaluate the susceptibility of metallic materials to environmentally assisted cracking. In: Annual Book of ASTM Standards, West Conshohocken. 1995.

[22] AMERICAN SOCIETY FOR TESTING AND MATERIALS. ASTM G49 - Standard practice for preparation and use of direct tension stress-corrosion test specimen. In:
Annual Book of ASTM Standards, West Conshohocken, USA, 2000.

[23] AMERICAN SOCIETY FOR TESTING AND MATERIALS. ASTM E8 - Standard test methods for tension testing of metallic materials. In: Annual Book of ASTM Standards, West Conshohocken, USA, 2000.

[24] ISHIYAMA, N., MAYUZUMI, M., MIZUTANI, Y., TANI, J-I. Stress Corrosion Cracking of Type 316 and 316L Stainless Steel in High Temperature Water. In: Proceedings of the $12^{\text {th }}$ International Conference on Environmental Degradation of Materials in Nuclear Power System - Water Reactors, 2005. Anais... TMS - The Minerals, Metals \& Materials Society, 2005. 